\title{
Building Maintenance Information Systems: The Adaptation of Context Aware Technology
}

\author{
Mohd Zulakhmar Zakiyudin, Mohamad Syazli Fathi, Siti Uzairiah Tobi, and Shuib Rambat
}

\begin{abstract}
Buildings maintenance activities have become more complex recently as they have evolved to be more sophisticated in design and functionality. Unreported failures and lack of timely maintenance of a building can lead to a disastrous outcome. Hence, various building maintenance management system tools must remain effective so that the right person at the right time and in the right place can have access to the right information. Thus, the best use of mobile technologies is critical to meet the needs of building maintenance. However, the applications only support the transfer of static existing building maintenance modes of data without considering the clients' differing settings. If users' wishes were context-aware, building maintenance applications could be made easy and responsive. This paper reviews developments in context-aware, building maintenance technology and how it can serve as a useful tool in building maintenance practices.
\end{abstract}

Index Terms-Building Maintenance, Facilities Management, Information System and Context-Aware Technology.

\section{INTRODUCTION}

Worldwide trade, extended levels of automation and the aspiration to apply lean production methods in-creases the demand for pervasive maintenance. Technology development in building maintenance started in the early 1970s. Since then, various aspects of development and growth have continued, including robotics, information technologies, and automation systems. As buildings become more complex in design and facilities, the maintenance department faces more challenges, which create opportunities for the parties involved to develop their products. The continuing flow of product development becomes more versatile as it involves constantly-developing technology.

\section{CURRENT TECHNOLOGIES SUPPORTING BUILDING MAINTENANCE MANAGEMENT}

Since the early 1970 s, the maintenance management process

Manuscript received January $21^{\text {st }}$, 2016. This work was financially supported by the National Institute of Valuation, Malaysia, under a National Real Estate Coordinator (NAPREC) research grant (UTM grant no: 4B086).

Mohd Zulakhmar Zakiyudin is with Twintech International University College of Technology, Sri Damansara Business Park, Persiaran Industri, Bandar Sri Damansara 52200 Kuala Lumpur

Mohamad Syazli Fathi is with UTM Razak School of Engineering \& Advanced Technology, Universiti Teknologi Malaysia, Jalan Sultan Yahya Petra, 54100 Kuala Lumpur, Malaysia

Siti Uzairiah Tobi is with UTM Razak School of Engineering \& Advanced Technology, Universiti Teknologi Malaysia, Jalan Sultan Yahya Petra, 54100 Kuala Lumpur, Malaysia

Shuib Rambat is with UTM SPACE, Universiti Teknologi MalaysiaJalan Sultan Yahya Petra, 54100 Kuala Lumpur, Malaysia has become increasingly dependent on computers. By the mid-1980s, maintenance organizations were using software developed for large mainframe computer systems [1].

The most popular activity for a computerized maintenance management system (CMMS) was financial monitoring and analysis followed by the maintenance scheduling, contract administration, and buildings and asset condition surveys [2]. A range of influential and advanced microcomputers was produced to deliver a proper framework for checking and overseeing statistical information [3]. However, there were requests for more microcomputer-based maintenance management support as a consequence of the extended access. To fulfil these requests, many software companies produced buildings and asset maintenance management programs. These products, albeit comparable in idea to the mainframe systems of the 1970 s as they utilize relational database development apparatuses to connect more subjects and elements in building and asset maintenance managements processes, were more extensive in nature [4], [5], [6] and [7]. A building automation system (BAS) is the automatic operation of building systems by sensors and controllers that are integrated in various ways [8].

In 1994, 3D visualization technology was applied to visualize facilities targeted for maintenance management work. The concept of 4D visualization was then introduced to reflect the state of a building through time by concentrating on the three aspects of lighting, painting and flooring [9]. A virtual reality model has been proposed to enhance visualization, which could be seen by an appropriate Virtual Reality Modelling Language (VRML). The simulator draws information from the outline objects analyzer in con-junction with the maintenance schedule analyzer [10].

A Virtual Reality model to support the maintenance of the walls in a building was developed within a research project in 2011. It enables the visual and interactive transmission of information related to the physical behavior of the elements [11]. In 1994 the knowledge of building maintenance could be represented in a variety of forms by using Artificial Intelligence (AI). The data on projects and components already installed by the Building Information Modelling (BIM) module could be recovered to distinguish all technical and maintenance data related to the building maintenance. BIM coordinated the case-based rea-soning for building maintenance to secure the con-version from 'Building Information Modelling' to 'Building Knowledge Modelling' in 2012. The effectiveness of Building Knowledge Modelling could be enhanced by the automation of data capture utilizing sensor technologies such as Radio Frequency Identification (RFID) [12].

In 1994, the material management system in maintenance work was improved through the bar-coding system and 
PDA-based data collection designed for application in maintenance inspection tasks [13] \& [14]. MAINtenance ForeCASTing in an Integrated Construction Environment (MAIN-CAST) was developed and proposed for forecasting the building element maintenance of a project as part of a fully integrated environment. MAIN-CAST aims to generate building element maintenance forecast valuations within a developed integrated construction environment prototype the Simultaneous Prototyping for an Integrated Construction Environment - (SPACE) [15].

Stanford University, through their Centre for Integrated Facility Engineering (CIFE), developed the Intelligent Real-Time Maintenance Management (IRTMM) System. The main target of this system is to perform the required value-based plant maintenance [16]. Efforts to provide facilities management knowledge support were made by Lund University through their KBS Media Lab by promoting the SERFIN Project. As a web-based facility, SERFIN would make all the building maintenance technical knowledge and experience easily available and accessible anytime and anywhere [17].

A building maintenance robot system based on a built-in guide rail was developed in 2012. In this system, a vertical climbing robot adopting a hook-based inchworm mechanism has been developed to perform the vertical climbing work of a horizontal moving robot by using a compact docking mechanism [18].

In 2013, InfoSPOT (Information Surveyed Point for Observation and Tracking) was recommended for building maintenance as a mobile Augmented Reality (AR) tool for accessing information about the facilities it helps maintain. A timeline for technology development in building maintenance is shown in Table 1.

TABLE I

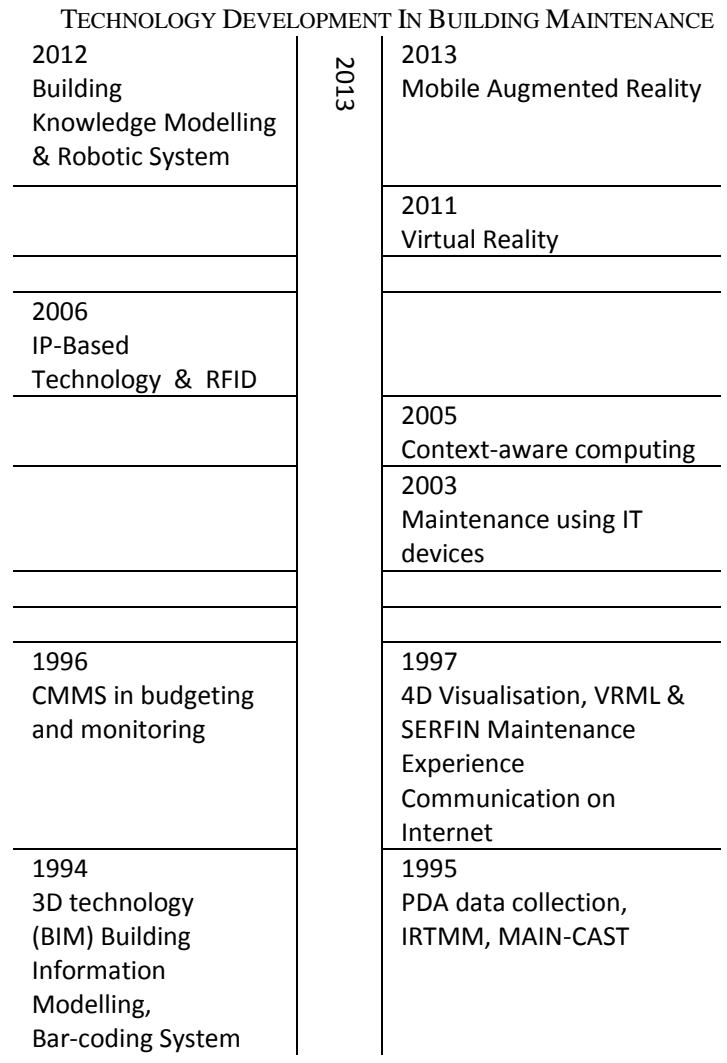

http://dx.doi.org/10.15242/IJRCMCE.IAE0316420

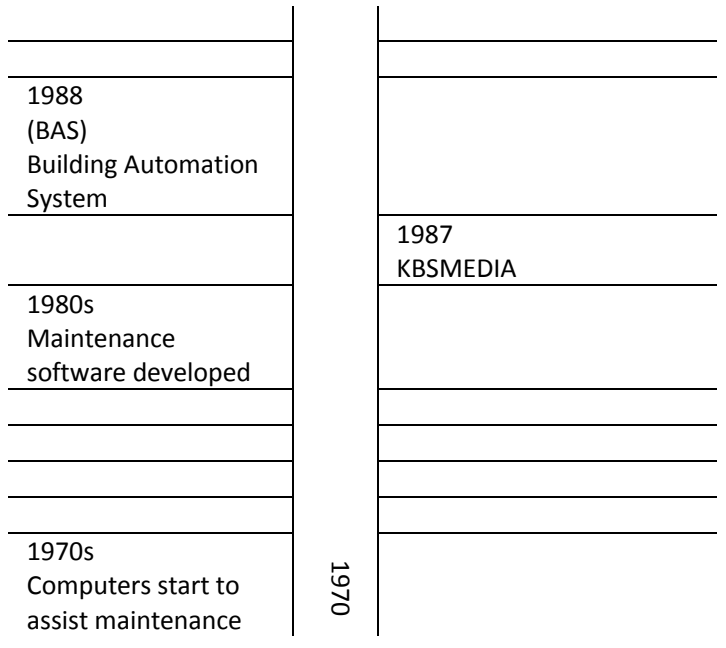

\section{CONTEXT-AWARE COMPUTING}

TABLE II

CONTEXT PARAMETERS.

\begin{tabular}{|c|c|}
\hline \multirow{4}{*}{ 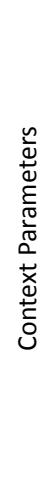 } & $\begin{array}{l}\text { Static Context } \\
\text { For example; } \\
\text { Client background, client interests, client preferences etc. }\end{array}$ \\
\hline & $\begin{array}{l}\text { Dynamic Context } \\
\text { For example; } \\
\text { Client location, client's recent tasks, location of other persons } \\
\text { or objects etc. }\end{array}$ \\
\hline & $\begin{array}{l}\text { Network Connectivity } \\
\text { For example; } \\
\text { Network characteristics, mobile terminal capabilities, } \\
\text { available bandwidth and quality of service etc. }\end{array}$ \\
\hline & $\begin{array}{l}\text { Environmental Context } \\
\text { For example; } \\
\text { time of day, noise, weather, etc. }\end{array}$ \\
\hline
\end{tabular}

Context-aware computing allows mobile devices to extract and execute a subset of activities in a process considering the contextual constraints [19]. Context-aware computing also utilizes the environ-mental attributes to inform the gadget about the objective provided by the client. This objective is related to the current and specific context provided by the specific information [20]. The client's static context; the client's dynamic context; network connectivity, available bandwidth, and service quality; and environmental context are four main areas of context parameters [21]. A table of context parameters is shown in Table 2. Context-aware computing has strongly interested computer science researchers. Thus, especially for mobile clients, this application has had positive impacts in various functions and places [22], [23], [24], [25], [26] \& [27]. The evidence from the Mobile Shadow Project (MSP) shows an emphasis on context parameters, such as location and data transmission [28]. A different method was applied in the AmbieSense Project where the developed environmental digital tag was aware of a person's occupancy, surroundings, and sensitivity and so responded accordingly [29]. A prototype to assist the progress of mobile learning was produced in 2003 [30]. In the Active Campus project a mock-up was created to display the prospective application capabilities for helping staff and students in an academic environment [31]. Meanwhile, in laboratory practices, the location-aware technologies were being used to retrieve and manage information [32]. A particular object or area was proximity-sensed either by means 
of Radio Frequency Identification (RFID) badges or immediate contact with a touch screen. By providing a mechanism for determining the particular context for relevant information, the awareness of the user context can enhance mobile computing applications in the Architecture, Engineering, Construction / Facilities Management (AEC/FM) sector. In recent years, mobile workers have been able to access in real-time different corporate back-end systems and multiple inter-enterprise data resources by the emergence of powerful wireless web technologies, coupled with the availability of improved bandwidth so as to enhance construction collaboration [33].

\section{CONTEXT-AwARE INFORMATION SYSTEMS}

The physical and virtual information are the result of context information subdivision [34]. This subdivision could also be enhanced to become static and dynamic information. As the majority of context information is dynamic; it must be accumulated continuously, frequently, and automatically. Additionally, the full state of the environment issues needs to be understood by past context information [35]. The understanding of context information itself, knowing about how the contextual information data is being captured, presented, and processed are key factors for a successful context-aware information system. The context of the usage may change rapidly as mobile handheld devices are used in dynamically varying situations. The sensors such as illumination or noise level, device applications, user's goals and information gained via connecting infrastructure are among the sources of information [36]. The context-aware application analyses and uses all the information sources to pro-vide specific information and services to the users. The site manager's mobile would confirm the delivery receipt after a wireless on-site network scans the tag attached to the bulk delivery and conveys a message as the delivery arrives at the buildings [37].

\section{CONCLUSION}

The technology improvement in the building maintenance management system has been rapidly upgraded. Technology and device development plus the availability of integration with the system make it easier for the developer to ensure that they really are on the right current track. The process of developing technology is likely to be on-going as the building and its facilities become more sophisticated over the years. The CMMS, sensor technology, the RFID or even robotic devices have shown their capabilities in building maintenance management systems. Context-aware computing has its own potential in this area as it can identify changes of location, staff and devices related to the current context.

\section{ACKNOWLEDGMENT}

This work was financially supported by the National Institute of Valuation, Malaysia, under a National Real Estate Coordinator (NAPREC) research grant (UTM grant no: 4B086).

\section{REFERENCES}

[1] Pettit, R. (1983), "Computers aid in the management of housing maintenance", Proceedings of BMCIS \& BRE Semi-nar, Feedback of Housing Maintenance, pp. 35-40.

[2] Jones, K. \& Collis, S, (1996) 'Computerised Maintenance Management Systems', Property Management, vol 14, No 4, 1996, ISSN 0263-7472.

[3] Atkin, B. (1987) "Computerizing information systems: a case study", in Spedding, A. (Ed.), Building Maintenance Economics and Management, E \& FN Spon, London,.

[4] Bates, R. (1987) "A maintenance information system", in Spedding, A.(Ed.), Building Maintenance Economics and Management, E \& FN Spon, London.

[5] Spedding, A. (1987), "Management of maintenance", in Spedding, A.(Ed.), Building Maintenance Economics and Management, E \& FN Spon, London.

[6] Jones, K. (1992), "The development of a computerized stock condition survey system using a range of commercial software tools - a case study", Innovations in Management, Maintenance \& Modernisation of Buildings, CIB W70 Sym-posium, Rotterdam, Vol. 9.

[7] Jones, K. and Burrows, C. (1994), "Data relationships in the stock condition survey process", CIB W70 Tokyo Symposium, Vol. 1, pp. 479-86.

[8] Eyke, M. (1988), Building Automation Systems: A Practical Guide to Selection and Implementation, BSP Professional Books.

[9] Farzad Khosrowshahi (1997), Visualisation of Building Maintenance Through Time, IEEE Conference on Information Visualization (IV '97).

[10] Rad, H.N. and Khosrowshahi, F. (1999) Visualization of the impact of time on internal flooring. In: Hughes, W (Ed.), 15th Annual ARCOM Conference, 15-17 September 1999, Liverpool John Moores University. Association of Researchers in Construction Management, Vol. 1, 363-72.

[11] Sampaio, Alcínia Z. (2012) Virtual Reality Technology Applied on Maintenance of Painted Walls of Buildings, Journal of Software Engineering and Applications. Retrived from:http://www.readperiodicals.com/201205/2692187871.html\#ixzz2 YoRuqUaY [Accessed 2nd June 2015].

[12] Arayici, Egbu and Coates (2012). Building information modelling (BIM) implementation and remote construction projects: Issues, Challenges and Critiques, ITcon Vol. 17, Special Issue Management of remote construction sites and the role of IT Systems, pg. 75-92.

[13] Baldwin, G. (1994) "Property Management In Hong Kong: An Overview", Property Management, (4), pp18-23. http://dx.doi.org/10.1108/02637479410071027

[14] Nathwani, S., and Shroff, A. (1995). Effective bridge maintenance using multimedia and mobile systems, Sixth International Conference on Structural Faults and Repairs, Lon-don, England.

[15] Alshavi, M. and Faraj, I. (1995) Integrating CAD and Virtual Reality in construction, Proceedings of the Virtual Reality and Rapid Prototyping for Engineering Conference, Salford University,.

[16] Kunz, J., Y. Jin, R. Levitt, S. - D. Lin, and P. Teicholz (1995), The Intelligent Real-Time Maintenance Management (IRTMM) System: Support for Integrated Value-Based Maintenance Planning, no. Technical Report No:100, 01/1995. Center for Integrated Facility Engineering, Stanford University.

[17] Christiansson (1997). Building Maintenance Knowledge Node. KBS-Media Lab, Lund University, Sweden. CIB W78 Workshop on "Information Technology Support for Construction Process Re-Engineering" Cairns, Australia July 9-11.

[18] Sung-Min Moon, Daehie Hong, Sung-Won Kim, Sora Park (2012). Building Wall Maintenance Robot Based on Built-in Guide Rail, IEEE International Conference on Industrial Technology 2012, 19 - 21 March 2012 Athens, Greece.

[19] Peng T, Armellin G, Betti D, Chiasera A, Toai TJ, Ronchetti M (2013). MDO: Framework for Context-Aware Process Mobility in Building-Maintenance Domain. 17th European Conference on Software Maintenance and Reengineering.

[20] Burrell, J. \& Gay, K. (2001) "Collectively defining context in a mobile, networked computing environment," CHI 2001 Extended abstracts, May2001.

[21] Pashtan, A. (2005). Mobile Web Services. Cambridge UK. Cambridge University Press. 
[22] Fleck, M.F., Kindberg, T., Brien-Strain, E.O., Rajani, R. and Spasojevic, M. (2002) "From informing to remembering: Ubiquitous systems in interactive museums". IEEE Pervasive Computing 1: pp.13-21. http://dx.doi.org/10.1109/MPRV.2002.1012333

[23] Marmasse, N., Schmandt, C. (2002) "A User-Centered Lo-cation Model. Personal and Ubiquitous Computing", Vol:5, No:6, pp:318-321,

[24] Aittola, M., Ryhänen, T., Ojala, T. (2003)“Smart Library Location-aware mobile library service", Proc. Fifth International Symposium on Human Computer Interaction with Mo-bile Devices and Services, Udine, Italy, pp.411-416. http://dx.doi.org/10.1007/978-3-540-45233-1_38

[25] Chen, H., Finin,T. \& Joshi, A. (2004) "Semantic Web in the Context Broker Architecture", IEEE Conference on Pervasive Computing and Communications, Orlando, March 2004, IEEE Press , pp. 277-286. http://dx.doi.org/10.1109/PERCOM.2004.1276865

[26] Coen, M.H. (1999) "The Future Of Human-Computer In-teraction or How I Learned to Stop Worrying and Love my In-telligent Room", IEEE Intelligent Systems 14(2): pp. 8-19.

[27] Laukkanen, M., Helin, H., Laamanen, H. (2002) "Tourists on the move", In Cooperative Information Agents VI, 6th Intl Workshop, CIA 2002, Madrid, Spain, Vol 2446 of Lecture Notes in Computer Science, pages 36-50. Springer, http://dx.doi.org/10.1007/3-540-45741-0_5

[28] Fischmeister, S., Menkhaus, G., Pree, W. (2002), "MUSA-Shadows: Concepts, Implementation, and Sample Applications: A Location-Based Service Supporting Multiple Devices",In Proc. Fortieth International Conference on Technology of Object-Oriented Languages and Systems, Sydney, Australia. 10. Noble, J. and Potter, J., Eds., ACS. pp. 71-79.

[29] Goker, A., Cumming, H. \& Myrhaug, H. I. (2004) Content Retrieval and Mobile Users: An Outdoor Investigation of an Ambient Travel Guide. Mobile HCI 2004 Conference, 2nd Intl Workshop on Mobile and Ubiquitous Information Access, Glasgow, UK.

[30] Lonsdale, P., Barber, C., Sharples, M., Arvantis, T. (2003) "A context-awareness architecture for facilitating mobile learning". In Proceedings of MLEARN 2003, London, UK.

[31] Griswold, W.G., Boyer, R., Brown, S.W., Truong, T.M., Bhasket, E., Jay, R., Shapiro, R.B. (2002) "Active Campus: Sustaining Educational Communities through Mobile Tech-nology", Uni. of California, Dept. of Computer Science and Engineering, Technical Report.

[32] Arnstein, L., Borriello,G., Consolvo,S., Hung, C. \& Su, J. (2002) "Labscape: A Smart Environment for the Laboratory", IEEE Pervasive Computing, Vol. 1, No. 3, pp. 13-21. http://dx.doi.org/10.1109/MPRV.2002.1037717

[33] Aziz, Z., Anumba, C.J., Ruikar, D., Carrillo., P.M., Bouch-laghem, D.N. (2005) "Context aware information delivery for on-Site construction operations," 22nd CIB-W78 Conf on ITin Construction, Germany, CBI Publication No:304.

[34] Barrett, K. \& Power, R. (2003) State of the Art: Context Management. [online] Waterford: M-Zones Available from http://www.m-zones.org/deliverables/d1_1/papers/4-01-context.pdf [Accessed 2nd June 2015]

[35] Candolin, C. \& Kari, H. H. (2003) An Architecture for Context Aware Management, Military Communications Con-ference (MILCOM 2003). IEEE, October 13-16, Boston, MA. p.237-241.

[36] Häkkilä, J. \& Mäntyjärvi, J. (2005) Collaboration in Con-text-Aware Mobile Phone Applications, Proceedings of the 38th Annual Hawaii International Conference on System Sci-ences (HICSS'05). IEEE, Hawaii. p.7. http://dx.doi.org/10.1109/HICSS.2005.145

[37] Anumba, C. and Aziz, Z. (2006). Case Studies of Intelligent Context-Aware Services Delivery in AEC/FM, Intelligent Computing in Engineering and Architecture, Lecture Notes in Computer Science Volume 4200, pp 23-31.

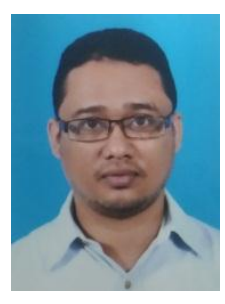

\section{Mohd Zulakhmar Zakiyudin.}

Malaysia, 1975.

Education:

Master of Science in Integrated Construction Project Management (Universiti Teknologi Mara, Malaysia, 2001)

Bachelor Degree in Building Surveying (Universiti Teknologi Mara, Malaysia, 2001)

Major field of study:

Building Maintenance and Facilities Management.

Principle Lecturer in Twintech International University College of Technology, Sri Damansara Business Park, Persiaran Industri, Bandar Sri Damansara 52200 Kuala Lumpur, Malaysia.

Current research interest; Context-Aware Technology on Computerized Maintenance Management System.

Published articles:

The Potential of Context-Aware Computing for Building Maintenance Management Systems, Applied Mechanics and Materials Vols. 405-408 (2013), Trans Tech Publications, Switzerland.

A Pilot Study of User-requirements for Building Maintenance Systems in Malaysian Higher Education Institutions, Applied Mechanics and Materials Vols 773-774 (2015), Trans Tech Publications, Switzerland. 